\title{
Radicals in Stereoselective Synthesis and Electron Transfer Reactions
}

\author{
Bernd Giese $\S^{\star}$ and Sonja Eckhardt
}

§Paracelsus Prizewinner 2012

\begin{abstract}
This short historical review describes the work of the Giese group on radicals and radical ions that has led to the award of the Paracelsus prize in 2012.
\end{abstract}

Keywords: Biopolymers $\cdot \mathrm{C}-\mathrm{C}$ bond formation $\cdot$ Electron transfer $\cdot$ Radicals $\cdot$ Stereochemistry

\section{Introduction}

The Swiss Chemical Society awarded the Paracelsus prize 2012 to Bernd Giese "for his pioneering work on stereoselective radical reactions in synthesis and his elaboration of the mechanism of electron transfer processes in biopolymers". This account will give a short, historical introduction into the synthetic and stereochemical work of the 'Giese reaction', and our ongoing work on electron transfer through biopolymers. The research demonstrates that radicals and radical cations can react with high selectivities.

\section{C-C Bond-forming Synthesis with Radicals}

This new synthetic method ('Giese reaction') was first published in 1977. ${ }^{[1]} \mathrm{We}$ studied its mechanism ${ }^{2]}$ and discovered that the process is a cyclic radical chain reaction (Scheme 1). ${ }^{[3]}$

Each radical $(\mathbf{1}, \mathbf{2}$ or 3$)$ attacks selectively one of the starting molecules $(\mathbf{4}, 5$ or 6) and generates a new chain-carrying intermediate. In order to avoid unwanted recombination of these radicals they have to react very fast with the starting material (reactivity condition). As the different intermediates in the chain shall undergo
${ }^{\star}$ Correspondence: Prof. Dr. B. Giese

Université de Fribourg

Département de chimie

Chemin du Musée 9

$\mathrm{CH}-1700$ Fribourg

Tel.: +4126300 8701

E-mail: bernd.giese@unifr.ch reactions with different educts, the radicals must show high and contrasting selectivities (selectivity condition). Thus, the challenge for an effective synthesis was to combine high reactivity with high selectivity. We worked out the substituent influence on the rate and selectivity of radical reactions, ${ }^{[2]}$ and applied the method to the synthesis of several target molecules. ${ }^{[3,4]}$

Quite early it became obvious that these intermolecular radical reactions not only occur with high substrate and regioselectivities but also with predictable stereoselectivities. ${ }^{[5]}$ In a joint effort together with Ned Porter and Dennis Curran, we elucidated the influence of chiral centers on the stereoselectivity of acyclic systems from the late 1980 s on. ${ }^{[6]}$ It was demonstrated how chiral auxiliaries, ${ }^{[6]}$ allylic strain effects, ${ }^{[7,8]}$ and Cram's (Felkin-Anh) rule ${ }^{[9]}$ govern radical chemistry (Fig. 1). An advantage of radicals for prediction of their stereoselectivities is that their ground states, whose conformations can be detected by ESR spectroscopy, ${ }^{[8 b]}$ are often energetically close to the transition states.

We applied this synthetic method also to carbohydrate chemistry, ${ }^{[10]}$ and this shifted our research interest in the early 1990s into the direction of DNA radical chemistry. During these experiments we became aware of electron transfer (ET) processes through double-stranded DNA.

\section{Electron Transfer through DNA}

In 1993, one year after Rudi Marcus received the Nobel prize for his theoretical work on ET processes, [11] Jackie Barton described her first experiments on long distance electron transfer through DNA. ${ }^{[12]}$ The question of how ET through DNA over long distances occurs launched a contro-

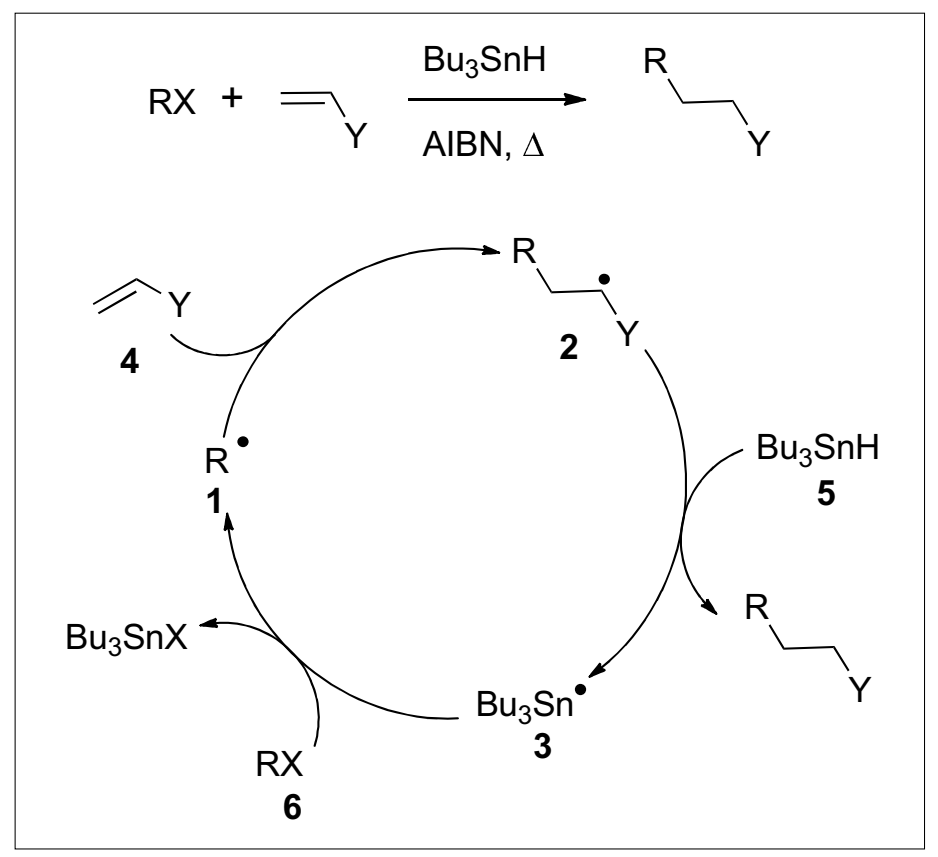

Scheme 1. Addition of C-radicals at olefins (Giese reaction). 


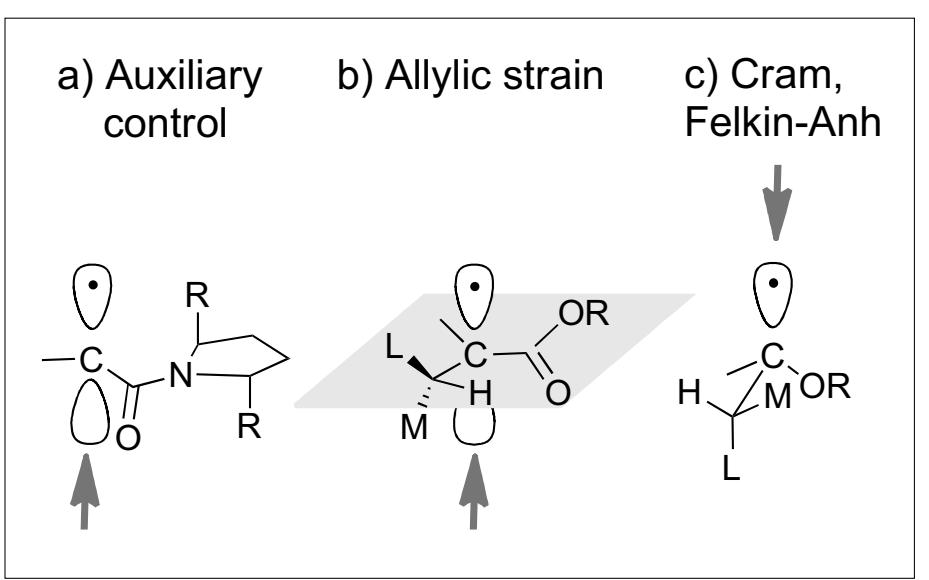

Fig. 1. Models that predict and explain the stereoselectivity of radical reactions. versial discussion. Theory predicts an exponential decrease of the ET rate $k$ with an increase of the distance between the electron donor and the electron acceptor (Eqn. (1), $k_{o}$ is the rate at contact distance $r_{o}, r$ is the distance between donor and acceptor, and $\beta$ is a 'material constant' that describes the distance influence on the rate of an ET reaction step).[11]

$$
k_{E T}=k_{0} \exp \left[-\beta\left(r-r_{0}\right)\right]
$$

In order to explain the observed weak distance influence unrealistically small $\beta$-values were suggested. In 1998, our experiments (together with Eric Meggers and Maria Michel-Beyerle) demonstrated that electron hole transfer through DNA over long distances occurs in a multistep hopping process using guanines $(\mathrm{G})$ as stepping stones (G-hopping). ${ }^{[13]}$ For short distances between the Gs the intervening adenins (A) serve as bridges, they are not oxidized as the oxidation potential of $\mathrm{A}$ is much higher than that of $G$. The overall rate follows the theory of random walk (diffusion of the charge). For reversible hopping steps $k_{\text {hop }}$ of the same rate and an irreversible last step the overall rate $k_{E T}$ is described by Eqn. (2), where $N$ is the number of the steps. ${ }^{[13,14]}$ As a consequence of this hopping mechanism the ET rate does not slow down in an exponential but in an algebraic fashion with the distance between donor and acceptor. In cases where the hopping steps occur with very different rates the slowest step becomes rate determining.

$$
k_{E T}=k_{h o p} / N^{2}
$$

Interestingly, each hopping step follows the Marcus rule (Eqn. (1)), and we determined a $\beta$-value of 0.7 for ET between guanines. ${ }^{[13]}$ This was in accord with laser experiments of Fred Lewis and Michael Wasielewski who measured intra- molecular ET rates between a G-base and photoexcited stilbene in 1997.[15] Charge hopping is faster than a single step (superexchange) reaction because instead of one long and therefore very slow reaction several very fast steps occur (Fig. 2).

The G-hopping mechanism has a limit as guanine radical cations are not only traps for electrons, they also react with the solvent water. Such a water trapping quench- es the $\mathrm{G}$ radical cation and stops ET.[16] Therefore the question remained how ET can occur if the G-bases are separated by long A:T-sequences. We solved the problem by an analysis of literature data in 2000 (together with Martin Spichty), and in a new experimental study. ${ }^{[17]}$ It turned out that in DNA sequences where more than two or three adenines separate the Gs, oxidation of the As to adenine radical cations start to compete with ET between Gs. In these sequences also As become hopping stations (A-hopping, Fig. 3). Interestingly, the trapping rate of guanine radical cations by water is slower than the oxidation rate of A (of course one can think of situations where other nucleophiles might change the picture).

In the early 2000s the groups of Michael Sevilla and Thomas Carell demonstrated that excess electron transfer uses the pyrimidine bases as hopping stations. ${ }^{[18]}$ This process differs slightly from electron hole transfer as the difference of the reduction potentials between cytosine (C) and thymine (T) is smaller than the oxida-
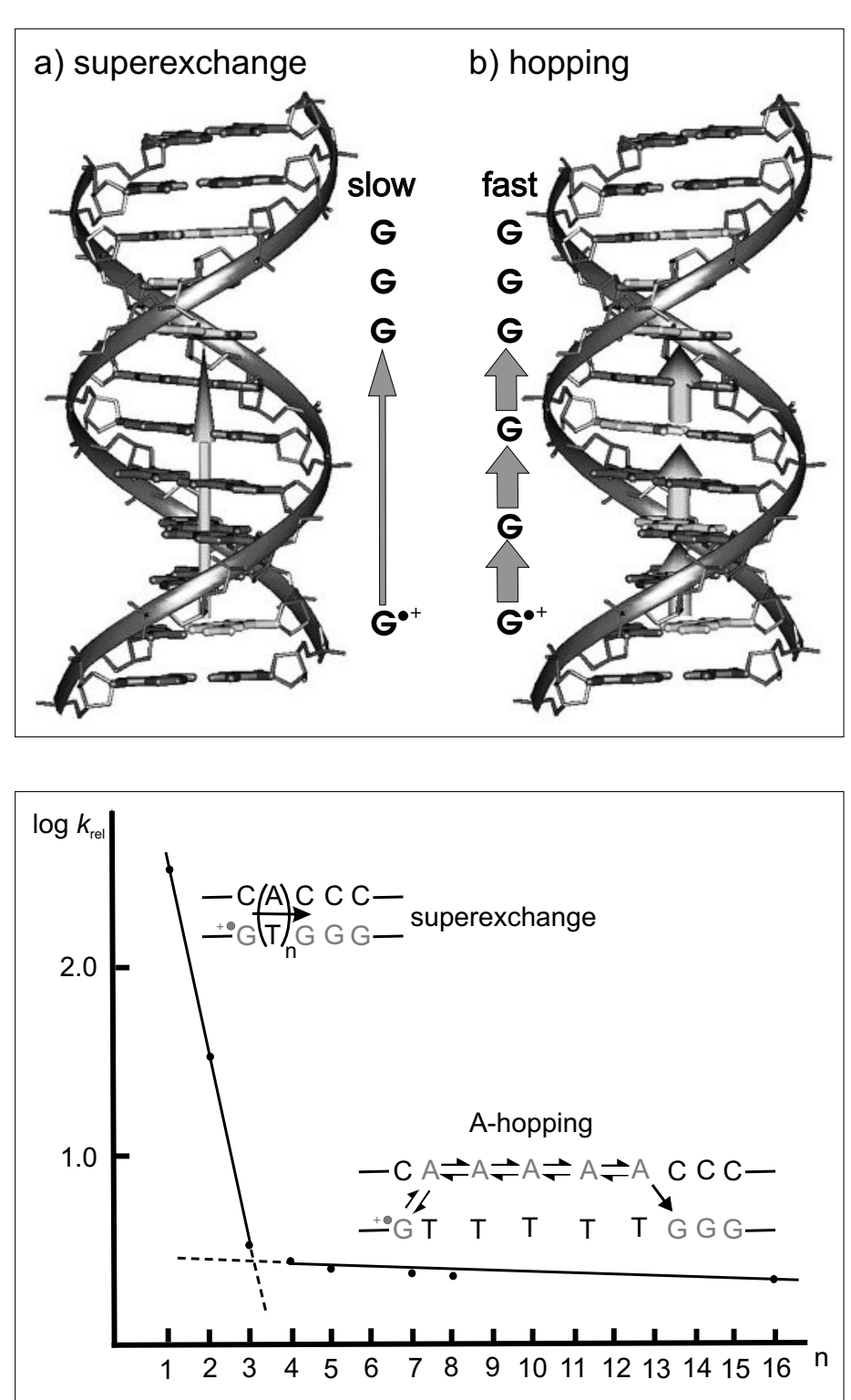

Fig. 2. Electron hole transfer through DNA via a) superexchange and b) G-hopping.
Fig. 3. ET through DNA via superexchange and A-hopping. 
tion potentials between the purine bases $\mathrm{G}$ and A. Our contribution to this area was the discovery that one electron can repair more than one T-photodimer, and that these dimers induce a conformational constraint into DNA so that the ET process has a preferred direction. ${ }^{[19]}$

\section{Electron Transfer through Peptides}

After having elucidated the major picture of ET in DNA, we became interested in studying long-distance ET through peptides as another class of biopolymers. These reactions are vital for all living organisms during energy conversion and metabolic processes.[20] From the pioneering work of Harry Gray it was obvious that longdistance ET through proteins is too slow if it would occur as a single step reaction. ${ }^{[21]}$ Indeed, studies of the enzymes ribonucleotide reductase ${ }^{[22]}$ as well as photolyase ${ }^{[23]}$ have shown that the aromatic side chains of tyrosine, tryptophan and histidine become stepping stones for a multistep hopping reaction. We have called them relay amino acids. In order to elucidate which amino acids can act as relay amino acids, we developed a versatile assay for the charge injection into peptides in 2005. [24] Laser irradiation generated peptide 7 that contains the radical cation of a substituted phenylalanine as electron acceptor (Fig. 4). Our experiments using transient UV/Vis spectroscopy for the determination of reactive intermediates showed that not only aromatic amino acids ${ }^{[25]}$ but also sulfur containing ones can act as stepping stones $^{[26]}$ for an ET hopping reaction. ${ }^{[27]}$

Next, we were interested in the influence of the dipole moment of PPII-helical peptides on the ET process. Already at the end of the last century, Marye Anne Fox showed that in $\alpha$-helical peptides ET is influenced by the overall dipole moment. ${ }^{[28]}$ Our experiments demonstrated, first in terms of yields ${ }^{[26]}$ and in 2011 also with regard to the observed ET rates ${ }^{[29]}$ that in PPII-helical peptides ET from the $\mathrm{N}$ - to the C-terminus is faster than in the opposite direction (Fig. 5). This is in accord with the calculated dipole moments, which are opposite in direction for PPII- compared to $\alpha$-helical peptides. ${ }^{[30]}$

In the same year, we were wondering to which extent the introduction of charges influences the ET rates along the peptide backbone considering that the dipole moment already has such an impact. Using similar model peptides with acetylated $(\mathbf{8 a})$ or protonated $\mathrm{N}$-termini $(\mathbf{8 b})$, it was shown that the ET rate between relay amino acid and N-terminal amino acid is influenced by the introduction of a positive charge at the N-terminus. ${ }^{[29]}$ For an ET proceeding in the direction $\mathrm{C} \rightarrow \mathrm{N}$, this ETrate is about one order of magnitude higher for the charged peptide (Fig. 6). This finding is in agreement with a change in the Coulomb repulsion. While in the neutral peptide the Coulomb energy remains unchanged during the ET process, the charge shift in the charged peptide $(\mathbf{8 b})$ leads to a difference in the Coulomb energy of approximately $3.0 \mathrm{kcal} \mathrm{mol}^{-1}$, which, according to the Marcus theory, corresponds to a rate enhancement of about ten and is in good agreement with our experimental result. [29]

The last important player in ET processes through peptides, which is currently under discussion in the literature, is the amide function itself as possible stepping stone. Shunsaku Kimura's electrochemical experiments in 2008 showed only a weak distance dependency for ET processes through $\alpha$-helical peptides that contained no aromatic side chains and were self-assembled on a gold surface. ${ }^{[31]}$ One possible explanation was a hopping mechanism, which uses the amide bonds of the peptide backbone as stepping stones, and in 2010 Kimura measured an oxidation potential of about $1.1 \mathrm{~V} v s$. NHE for the amide bond in $\alpha$-helical peptides. ${ }^{[31 b]}$ In the same year, Robert Cukier published calculations that supported the suggestion of amide bond participation in ET processes through $\alpha$-helical peptides because their large dipole moments reduce the oxidation potential of the amide groups. ${ }^{[32]}$ In 2012 , we set out to investigate the special role of $\alpha-/ 3_{10}$-helical peptides in ET processes. ${ }^{[33]}$ Kinetic laser experiments were performed with peptides of different secondary structure (PPII-helical peptide and $\alpha-/ 3_{10}$-helical peptide) that carried our radical cation as electron acceptor with an oxidation potential of $1.3 \mathrm{~V} v s$. NHE at the C-terminal end. It turned out that this oxidation potential is high enough to oxidize the amide bonds in $\alpha$-helical peptides, and our results were in accord with a mechanism where the amide groups of $\alpha-/ 3_{10}$-helical peptides function as stepping stones and transport the charge along the peptide backbone as exemplified in Fig. 7.
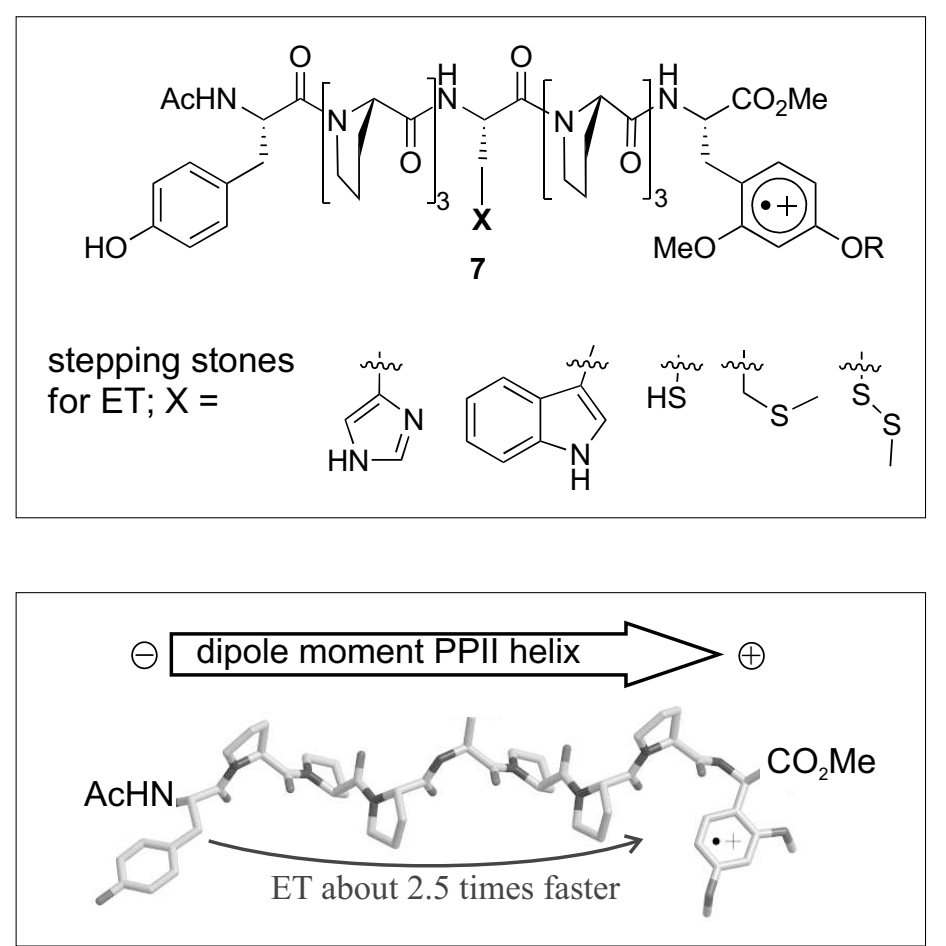

Fig. 5. ET through PPII-helical peptides. ET from the $\mathrm{N}$ - to the C-terminal end is 2.5 times faster than in the opposite direction.

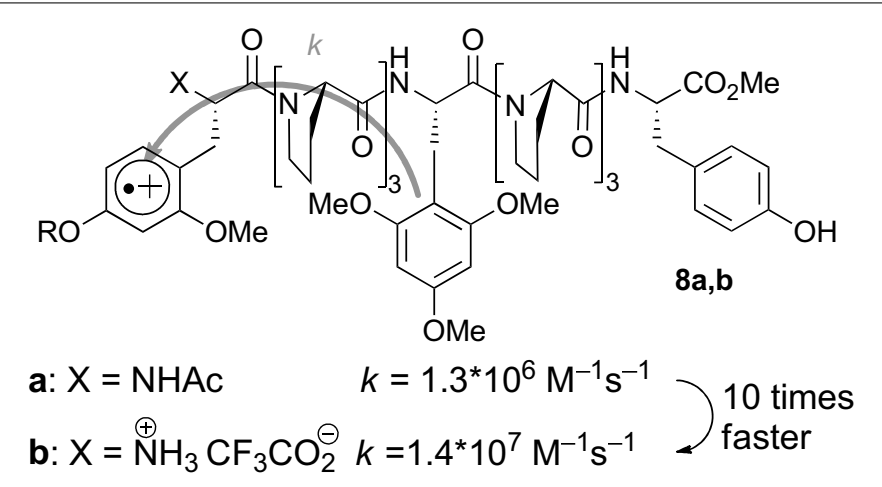

Fig. 4. PPII-helical peptide 7 with side chains $X$ suitable as stepping stones in an ET process.
Fig. 6. Influence of a positive charge on ET rates for ET from the $\mathrm{C}$ - to the $\mathrm{N}$-terminal end in PPII-helical peptides. 


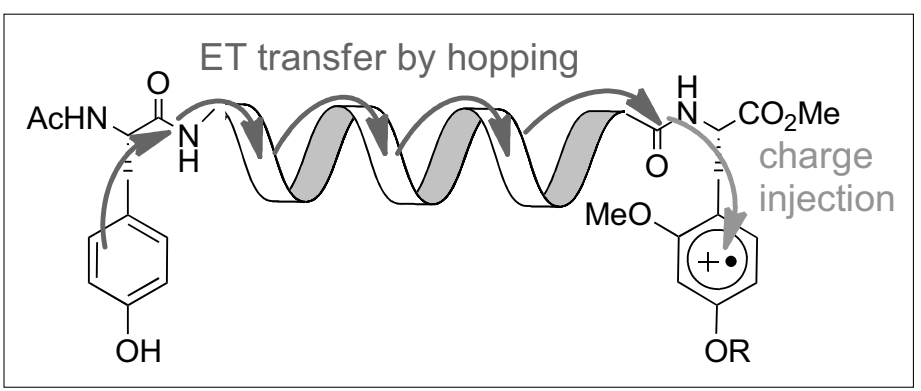

Fig. 7. ET through $\alpha / 3_{10}$-helical peptides. Charge injection into the amide group of the backbone is followed by ET transfer along the backbone using the amide groups as stepping stones.
All the aforementioned modulators for ET through peptides, namely i) sidechain participation, ii) charge introduction, and iii) $\alpha-/ 3_{10}$-helical conformation, can be used to explain complex processes currently under discussion in the scientific literature such as mineral respiration by anaerobic bacteria. In 2012, Gemma Reguera published the molecular and electronic structure of bacterial pilin (proteins containing 61 amino acids), which self-assemble into pili.[34] The latter are required for the growth of Geobacter sulfurreducens with $\mathrm{Fe}$ (III) oxides since they are thought to be responsible for the ET between the interior of the cell and the extracellular electron acceptor Fe(III). All three modulators for long-distance ET by a hopping mechanism in peptides can indeed be found in the pilin since they are mainly $\alpha$-helices and contain aromatic as well as charged side chains. Due to the self-assembly of pilin subunits into pili, the subunits come close to each other, allowing the electron to travel from one pilin to the other and hence from the cell interior to mineral salts outside of the cell.

Received: February 6, 2013

[1] a) B. Giese, J. Meister, Chem. Ber 1977, 110 2558 ; b) A. Hassner, C. Stumer, 'Organic Syntheses Based on Name Reactions', Pergamon, Amsterdam, Boston, 2002.

[2] B. Giese, Angew. Chem. Int. Ed. 1983, 22, 753.
[3] a) B. Giese, J. Meixner, Tetrahedron Lett. 1977, 18, 2779; b) B. Giese, Angew. Chem. Int. Ed. 1985, 24, 553.

[4] See for example: a) D. B. Gerth, B. Giese, J. Org. Chem. 1986, 51, 3726; b) B. Giese, J. Dupuis, M. Nix, Org. Synth. 1987, 65, 236.

[5] a) B. Giese, J. Meixner, Tetrahedron Lett. 1977, 18, 2783; b) B. Giese, K. Heuck, H. Lenhardt, U. Lüning, Chem. Ber. 1984, 117, 2132; c) B. Giese, Angew. Chem. Int. Ed. 1989, 28, 969.

[6] a) N. A. Porter, D. M. Scott, B. Lacher, B. Giese, H. G. Zeitz, H. J. Lindner, J. Am. Chem. Soc. 1989, 111, 8311; b) N. A. Porter, B. Giese, D. P. Curran, Acc. Chem. Res. 1991, 24, 296.

[7] B. Giese, M. Zehnder, M. Roth, H. G. Zeitz, J. Am. Chem. Soc. 1990, 112, 6741.

[8] a) B. Giese, M. Bulliard, H.-G. Zeitz, Synlett 1991, 1991, 425; b) B. Giese, W. Damm, F. Wetterich, H.-G. Zeitz, Tetrahedron Lett. 1992, $33,1863$.

[9] a) B. Giese, W. Damm, J. Dickhaut, F. Wetterich, S. Sun, D. P. Curran, Tetrahedron Lett. 1991, 32, 6097; b) B. Giese, W. Damm, M. Roth, M. Zehnder, Synlett 1992, 1992, 441.

[10] a) B. Giese, J. Dupuis, Angew. Chem. Int. Ed. Engl. 1983, 22, 622; b) B. Giese, T. Witzel, Angew. Chem. Int. Ed. Engl. 1986, 25, 450; c) B. Giese, M. Hoch, C. Lambert, R. R. Schmidt, Tetrahedron Lett. 1988, 29, 1375; d) B. Giese, Pure and Appl. Chem. 1988, 60, 1655; e) B. Giese, T. Linker, Synthesis 1992, 46.

[11] R. A. Marcus, Angew. Chem. Int. Ed. 1993, 32 , 1111.

[12] C. Murphy, M. Arkin, Y. Jenkins, N. Ghatlia, S. Bossmann, N. Turro, J. Barton, Science 1993 262,1025

[13] a) E. Meggers, M. E. Michel-Beyerle, B. Giese, J. Am. Chem. Soc. 1998, 120, 12950; b) B. Giese, Acc. Chem. Res. 2000, 33, 631.

[14] J. Jortner, M. Bixon, T. Langenbacher, M. E. Michel-Beyerle, Proc. Natl. Acad. Sci. U.S.A. 1998, 95, 12759.
[15] F. D. Lewis, T. Wu, Y. Zhang, R. L. Letsinger, S. R. Greenfield, M. R. Wasielewski, Science 1997, 277, 673 .

[16] B. Giese, Top. Curr. Chem. 2004, 236, 27.

[17] a) B. Giese, M. Spichty, Chem. Phys. Chem. 2000, 1, 195; b) B. Giese, J. Amaudrut, A.-K. Kohler, M. Spormann, S. Wessely, Nature 2001, $412,318$.

[18] a) Z. Cai, Z. Gu, M. D. Sevilla, J. Phys. Chem. B 2000, 104, 10406; b) C. Behrens, L. T. Burgdorf, A. Schwögler, T. Carell, Angew. Chem. Int. Ed. 2002, 41, 1763.

[19] B. Giese, B. Carl, T. Carl, T. Carell, C. Behrens, U. Hennecke, O. Schiemann, E. Feresin, Angew. Chem. Int. Ed. 2004, 43, 1848.

[20] B. Giese, S. Eckhardt, M. Lauz, 'Encyclopedia of Radicals in Chemistry, Biology and Materials', Ed. C. Chatgilialoglu, A. Studer, John Wiley \& Sons, Chichester, West Sussex, Hoboken, N.J, 2012.

[21] H. B. Gray, J. R. Winkler, Q. Rev. Biophys. 2003, 36, 341.

[22] J. Stubbe, D. G. Nocera, C. S. Yee, M. C. Y. Chang, Chem. Rev. 2003, 103, 2167.

[23] C. Aubert, M. H. Vos, P. Mathis, A. P. M. Eker, K. Brettel, Nature 2000, 405, 586.

[24] a) B. Giese, M. Napp, O. Jacques, H. Boudebous, A. M. Taylor, J. Wirz, Angew. Chem. Int. Ed. 2005, 44, 4073; b) M. Cordes, O. Jacques, A. Köttgen, C. Jasper, H. Boudebous, B. Giese, Adv. Synt. Catal. 2008, 350, 1053.

[25] M. Cordes, A. Köttgen, C. Jasper, O. Jacques, H. Boudebous, B. Giese, Angew. Chem. Int. Ed. 2008, 47, 3461.

[26] M. Wang, J. Gao, P. Müller, B. Giese, Angew. Chem. Int. Ed. 2009, 48, 4232.

[27] B. Giese, M. Wang, J. Gao, M. Stoltz, P. Müller, M. Graber, J. Org. Chem. 2009, 74, 3621.

[28] a) M. A. Fox, E. Galoppini, J. Am. Chem. Soc. 1997, 119, 5277; b) E. Galoppini, M. A. Fox, J. Am. Chem. Soc. 1996, 118, 2299.

[29] J. Gao, P. Müller, M. Wang, S. Eckhardt, M. Lauz, K. M. Fromm, B. Giese, Angew. Chem. Int. Ed. 2011, 50, 1926.

[30] H. Kuemin, S. Schweizer, C. Ochesenfeld, H. Wennemers, J. Am. Chem. Soc. 2009, 131, 15474

[31] a) M. Kai, K. Takeda, T. Morita, S. Kimura, J. Pept. Sci. 2008, 14, 192; b) Y. Arikuma, H. Nakayama, T. Morita, S. Kimura, Angew. Chem. Int. Ed. 2010, 49, 1800.

[32] X. Chen, L. Zhang, L. Zhang, W. Sun, Z. Zhang, H. Liu, Y. Bu, R. I. Cukier, J. Phys. Chem. Lett. 2010, $1,1637$.

[33] M. Lauz, S. Eckhardt, K. M. Fromm, B. Giese, Phys. Chem. Chem. Phys. 2012, 14, 13785.

[34] G. T. Feliciano, A. J. R. da Silva, G. Reguera, E. Artacho, J. Phys. Chem. A 2012, 116, 8023. 